This is the author's final, peer-reviewed manuscript as accepted for publication. The publisher-formatted version may be available through the publisher's web site or your institution's library.

\title{
One more time with feeling: a rejoinder to Clair's and Wood's responses
}

Jess K. Alberts, Sarah E. Riforgiate, Sarah Tracy, Angela Trethewey

\section{How to cite this manuscript}

If you make reference to this version of the manuscript, use the following information:

Alberts, J. K., Riforgiate, S. E., Tracy, S., \& Trethewey, A. (2011). One more time with feeling: A rejoinder to Clair's and Wood's responses. Retrieved from http://krex.ksu.edu

\section{Published Version Information}

Citation: Alberts, J. K., Riforgiate, S. E., Tracy, S., \& Trethewey, A. (2011). One more time with feeling: A rejoinder to Wood's and Clair's commentaries. Journal of Family Communication, 11(1), 60-63.

Copyright: Copyright $\odot$ Taylor \& Francis Group, LLC

Digital Object Identifier (DOI): doi:10.1080/15267431.2011.535464

Publisher's Link:

http://www.tandfonline.com/doi/full/10.1080/15267431.2011.535464\#.UvPILT1dXL8

This item was retrieved from the K-State Research Exchange (K-REx), the institutional repository of Kansas State University. K-REx is available at http://krex.ksu.edu 
One More Time with Feeling: A Rejoinder to Clair's and Wood's Responses

Jess K. Alberts, Sarah E. Riforgiate, Sarah Tracy, Angela Trethewey

One of the many interesting aspects of studying the division of domestic labor is the strong, even visceral, reactions people have to the topic (and to our theoretical conceptualization of it). Sometimes we feel like the poor benighted fool who introduces politics at the family Thanksgiving dinner only to discover that everyone has an opinion, feels strongly about that opinion and is unerringly convinced that her/his position is incontrovertibly the right one. Having a dispassionate conversation regarding domestic labor can be quite difficult, but we believe it is essential that we do so and is one reason we developed our integrated theory.

Like our reviewers, we became engaged in the conversation on the division of domestic labor due to strongly held beliefs about fairness, justice, sex roles, and relationships as well as, especially for us, concern about the high levels of conflict that attend the performance of and conversations about domestic labor. Once so engaged, we attempted to develop a theory that removes some of the emotionality from the study of domestic labor in the hopes of making it easier to talk about and resolve disparities, as well as improve relationships. In some ways we believe we have succeeded, and in others perhaps not, as our reviewers' comments suggest.

Those comments, as well as those of Editor Caryn Medved and an anonymous reviewer, have provided and continue to provide us with ways to sharpen our ideas and their presentation as we move forward. Our reading of the most recent critiques presented in this volume have lead us to recognize which of our ideas and positions need additional clarification, to identify ideas that we will consider as we research and revise our theory, 
and to question how the insights offered help people talk about and negotiate domestic labor right now. Although we cannot respond to all of the comments that sparked our reactions or the totality of the critiques offered by Professors Wood and Clair, we would like to respond to a few central arguments they presented.

Perhaps the critique that sparked the strongest response in us and which we felt most misrepresented our perspective on the division of labor was the claim by Professor Wood that we were establishing a ruler and that the ruler was a female one. We would like to take up both of these issues. First, we do not believe we are setting up a ruler or standard for the appropriate performance of domestic labor. We conceptualize threshold level as an individual characteristic that varies widely and that becomes contested only when two individuals with disparate threshold levels live together. This does not necessarily mean that one person is very neat, clean, and tidy and that the other is not; in fact, both people objectively could be quite clean or quite messy and dirty. Problems related to the division of domestic labor arise, we argue, because there is a discrepancy between dyadic members' thresholds and that one becomes an over-performer or underperformer only in relation to one's partner - not in relation to an objective standard. Thus, the person with the lowest threshold level in a dyad of two people with very high thresholds likely still will become an over-performer in comparison to his or her partner. In sum, we argue that what Professor Wood describes as a "ruler" is not ours to create but rather is specific to each dyad and typically established by the partner with the lowest threshold level, which leads us to her second issue, that the ruler is female in its orientation. 
Although we certainly make the case that women in heterosexual dyads often bear the burden of being over-performers and many may in fact possess lower threshold levels, perhaps in as many as a third of heterosexual cohabiting couples the male partner has a lower threshold and potentially is the over-performer (Chethik, 2006). Our theory includes sex and gender as contributing to discrepancies in performance for two reasons: women may be disposed to having lower threshold levels and to having been socialized to have greater competencies; but fundamentally the issue is an individual one. And again, the ruler likely is created by whichever partner has the lower tolerance for dirt and disorder, be it a woman or a man.

Relatedly, Professor Wood suggests that our theory is biased toward the overperformer's rule or standard. Although we disagree, we believe she makes a legitimate argument that this not sufficiently clear until the end of the paper. We do not think the over-performer's standards are those that must be met by both members of the dyad, but we recognize that threshold level is a driver of behavior and can feel quite compelling. Thus, a lower threshold drives an individual to over-perform and consequently to feel overworked and underappreciated as well disadvantaged professionally, interpersonally, and personally. Such behavior creates an imbalance within the dyad because the underperforming partner's threshold is rarely met, and in turn she/he benefits in a variety of ways from being paired with a lower threshold partner, a situation that could turn on a dime if she or he were paired with a different partner. In sum, we see the problems created by discrepancies in threshold level and subsequent performance as a distinctly dyadic one which requires a dyadic response. 
Our response to Professor Clair's critique is somewhat different. We absolutely agree that "a rhetorical theory of domestic labor ... is not necessarily antithetical to the integrative theory ... rather it may provide a supporting communication-oriented explanation for the continuing troublesome meanings and messages that far too often arise surrounding the division of labor (domestic and otherwise)" (p. 2). Where we diverge is in the desire for our theories to offer insight versus redress. Clair's perspective allows for critique and analysis of potential interpretations but is less focused on providing a framework to assess the basis for those narratives and couples' behaviors, nor does it specify how to improve choices and communication between relational partners over this contentious issue. While a narrative approach provides a way to understand couples' interpretations of their experience, we believe a distinct value of our integrative theory is in helping to explain behavior. People very often use narrative constructions to justify behaviors, but that doesn't mean those narratives always reflect what they do or why they do it. Our theory, however, can shed light on behaviors (and their causes) in a way that illuminates individual and dyadic choices with the goal of helping couples develop interactional patterns and interpretive structures that assist them in resolving conflicts over the division of domestic labor. Despite these differences, we see great value in tying our insights back to narrative constructions, because both influence how people understand and respond to their own and others' lives and choices.

In addition, Clair usefully points out how narrative stories play a role in conflict. Namely, when dyads approach the same issue with a different rhetorical construction (e.g., “dusting is not a job I own,” versus “when he doesn’t dust, he is saying he doesn’t care”) there is bound to be conflict. Clair suggests that if couples shared the same 
narrative, there would not be as much conflict and illustrates this argument by rhetorically analyzing Noah’s comment:

Hang on a minute. I never asked her to do anything of those things.

I can’t help it if she has higher standards than I do. I don't care what we have for dinner. I don’t care if the floor gets mopped twice a week.

She argues that in saying this, the man shows that he does not desire any part of this “Martha Stewart-esque” rhetorical construction of who they are as a couple. We certainly concur that relational conflict and resentment occur because of a mismatch in stories. However, we would like to point out something that she glosses: Namely, one story has much more power than another. Because domestic labor has traditionally been the province of women, its narrative has less credence and more justification is necessary for it. Indeed, as Clair points out, Durkheim even linked domestic labor with a regression in cranial capacity.

If, in contrast, domestic labor was associated with high pay, power and respect, then our discussion of it would be quite different. In order to illustrate this point, let's deconstruct Noah’s statement above. Let’s assume an employee were to say to a boss when the boss complained about the employee's performance in meeting some goal:

I never asked the boss to achieve anything of those things. I can't help it if the boss has higher standards than I do. I don't care whether we meet those goals. I don't care if the goals get met this week or next week.

If an employee were to say this, she or he would likely be judged a lazy employee worth firing. Indeed, the boss would likely say, "You obviously can’t hack the business world, get out!” However, it seems from some of the responses by Clair and Wood that they, 
instead, would react by thinking, "Well, the boss is just an over-performer and needs to relax a little. If an employee doesn't want to work as hard as the boss, then that's just as much the boss's problem as the employee's.” At least in today's world, such a reaction would not be seen as legitimate. And, just as underperformers at work are usually not allowed a free pass, we believe it makes sense to critically examine underperformance in the private sphere.

This circles back to the fact that we believe the critiques of our theory are sidestepping an important premise of conflict about domestic labor-and that is that domestic labor when performed in one's own home is not rewarded with material benefits. Therefore, until such time that domestic labor is valued in the same way as work in the public sphere, we believe it's important to redress inequalities. Namely, when overperformers (mostly women), regularly do the lion's share of domestic labor, injustice ensues—and there's good reason to develop a theory and an explanation that might attempt to rectify this injustice.

Finally, we must respond to Wood's critique of our less than sanguine view of the potential for change in how men and women are socialized regarding the performance of domestic labor. Of course, such change is what we hope for and believe is possible. However, though such change may seem inevitable and quick from an historical perspective, years and decades of waiting for it likely does not feel swift and is of little benefit to those individuals and marriages/relationships that are suffering from that lack of change in the here and now. We believe that if dyads use our theory right now to understand and guide their divisions of domestic labor, such behaviors can help create social change. As children see more equitable divisions of labor and/or understand that 
threshold level (not biological sex) drives one’s performance of domestic labor, perhaps social change will occur that much more quickly.

At this juncture, we are poised to move forward in assessing the claims our theory offers and to refine the theory on the basis of those assessments and the excellent critiques and feedback offered by Professors Caryn Medved, Robin Clair, Julia Wood and an anonymous reviewer. We greatly appreciate your intellectual contributions and the considerable time and energy you have devoted to improving our project and our work yet to come.

\section{Reference}

Chethik, N. (2006). VoiceMale: What husbands really thing about their marriages, their wives, sex, housework, and commitment. New York: Simon \& Shuster. 